\title{
Extraction of fish oil from the skin of Indian mackerel using supercritical fluids.
}

\begin{abstract}
The total oil was extracted from the ground skin of Indian mackerel (Rastrelliger kanagurta) using various techniques of supercritical fluid extraction (SFE) at $20-35 \mathrm{MPa}$ and $45-75{ }^{\circ} \mathrm{C}$ and by the Soxhlet method for comparison. The oil yield increased with pressure and temperature and the highest yields were 24.7, 53.2, 52.8, and 52.3/100 g sample (dry basis) for the continuous, cosolvent, soaking, and pressure swing techniques, respectively, at 35 $\mathrm{MPa}$ and $75{ }^{\circ} \mathrm{C}$. The yield from the Soxhlet extraction was 53.6/100 g sample (dry basis). The CO2 consumption was 581.8, 493.6, 484.9 and $290.9 \mathrm{~g}$ for the continuous, cosolvent, soaking and pressure swing techniques, respectively, at $35 \mathrm{MPa}$ and $75{ }^{\circ} \mathrm{C}$. The largest recoveries of PUFA, especially the $\omega-3$ family, were achieved from the soaking and pressure swing techniques at $35 \mathrm{MPa}$ and $75^{\circ} \mathrm{C}$. Thus, the pressure swing and soaking techniques are the most effective at extracting the oil from fish skin.
\end{abstract}

Keyword: Fish oil; Supercritical extraction; Cosolvent technique; Soaking technique; Pressure swing technique. 